\title{
Pandemi Sürecinde Yürünebilir Sokaklar ve Mahalle Donatılarına Erişilebilirlik Üzerine Bir Değerlendirme
}

\author{
Kübra Cihangir Çamur ${ }^{1}$ \\ ORCID: 0000-0003-0343-3306
}

Nilgün Görer Tamer ${ }^{3}$

ORCID: 0000-0001-6502-3105

\author{
Fatma Erdoğanaras ${ }^{2}$ \\ ORCID: 0000-0002-0892-8431 \\ Gülsel Satoğlu 4 \\ ORCID: 0000-0003-4601-2034
}

Öz

2019'un sonunda başlayan ve yaklaşık iki yıldır tüm dünyayı etkisi altına Covid-19 Pandemisi, insanlar konutlarından çıkmama, çıkarsa da yürüme mesafesiyle sınırlamaya kadar uzanan uygulamalara maruz birakt. "Yeni normal" olarak hayatımiza giren sosyal mesafe ise kentin ve kentsel mekanlarn, donatıların planlanması ve tasarlanmasının yeniden düşünülmesine neden oldu. Yaşam pratiğindeki bu köklü değişimler kaçınılmaz olarak mahalle ve sokak kurgusunu sorgulatmış, mahalle ölçeğini yeniden planlama ve tasarımın odağına çekmiştir. Bu salgin süreci, kalabaliklardaki bulaş riskinden kaçınmak isteyen insanların toplu taşıma araçlarından kaçınmasıyla da öne çıktı. Böylece toplumun geniş kesimleri bireysel ulaşımın yan sıra yürüyüş, bisiklet gibi sağllkl ulaşım seçeneklerine her zamankinden daha fazla yöneldi. Özellikle kapanma ve sokağa sınırl çıkı̧ dönemlerinde, günlük ihtiyaçların en kısa mesafelerde karşılayıp, konutlarına dönmek durumunda kaldılar. Yaşanılan bu değişimler esnasında, gündelik yaşam "mahalle kurgusu, donatıların erişilebilirlĭ̆i ve yürünebilir sokaklar" çerçevesinde yeniden sorgulanmaya başlandı. Bu makalenin amacı, öncelikle erişilebilir donatılara ve kentsel yaşamın parçaların birbirine bağlayan yürünebilir sokaklara sahip bir mahallenin ve mahalle ölçeğinde planlamanın, tasarımın ne denli önemli olduğunu, ikinci olarak bu mahallelerin yaşam kalitesine sağlayabileceğgi katklları pandemi süreci ve gelecekte benimsenecek yaklaşımlar ile ilişkilendirerek ortaya koymaktır.

Anahtar Kelimeler: Mahalle, yürünebilir sokaklar, erişilebilirlik, Covid-19, pandemi, kent planlama.

\footnotetext{
${ }^{1}$ Doç. Dr., Gazi Üniversitesi, E-mail: ccamurster@gmail.com

${ }^{2}$ Doç. Dr., Gazi Üniversitesi, E-mail: fatmaerdoganaras1862@gmail.com

${ }^{3}$ Prof. Dr., Gazi Üniversitesi, E-mail: nilgungorertamer@gmail.com

${ }^{4}$ Yüksek Lisans Öğr., Gazi Üniversitesi, E-mail: gulsel88.satoglu@gmail.com

idealkent @ Kent Araştırmaları Dergisi (Journal of Urban Studies) 


\title{
An Insight to Walkable Streets and Accessibility of Neighbourhood Amenities during the Covid-19 Pandemic
}

\author{
Kübra Cihangir Çamur ${ }^{5}$ \\ ORCID: 0000-0003-0343-3306 \\ Nilgün Görer Tamer 7 \\ ORCID: 0000-0001-6502-3105
}

\author{
Fatma Erdoğanaras 6 \\ ORCID: 0000-0002-0892-8431 \\ Gülsel Satoğlu ${ }^{8}$ \\ ORCID: 0000-0003-4601-2034
}

\begin{abstract}
The Covid-19 Pandemic has affected the whole world for about two years, and has exposed people to closure practices ranging from not leaving their homes or limiting them to walking distance. Social distancing and the "new normal" have led to a rethinking of planning and design of the city and urban spaces and neighbourhood amenities. This Pandemic is marked by people's avoidance of public transport as remedy for the risk of contamination by crowds. Thus, large segments of society have turned to healthy transportation options such as walking and cycling, more than ever before. They have to meet their daily needs in the shortest distances, especially during the periods of closure and limitations. Throughout these radical changes, daily life is questioned within the framework of "neighbourhood design, accessibility of neighbourhood amenities and walkable streets". The aim of this article is firstly to reveal vitality of a neighbourhood, and planning and design with accessible amenities and walkable streets for individual and public health by associating it with the Pandemic Process, and secondly to discuss the contributions that such neighbourhoods can provide to the quality of life.
\end{abstract}

Keywords: Neighborhood, walkable streets, accessibility, COVID-19, pandemic, urban planning.

\footnotetext{
${ }^{5}$ Assoc. Prof. Dr., Gazi University, E-mail: ccamurster@gmail.com

${ }^{6}$ Assoc. Prof. Dr., Gazi University, E-mail: fatmaerdoganaras1862@gmail.com

7 Prof. Dr., Gazi University, E-mail: nilgungorertamer@gmail.com

${ }^{8}$ Graduate Student, Gazi University, E-mail: gulsel88.satoglu@gmail.com

idealkent @ Kent Araştırmaları Dergisi (Journal of Urban Studies) 


\section{Giriş}

COVID-19'un Dünya Sağllk Örgütü (WHO) tarafından pandemi ilan edildiği ve dünya çapında 118.000 vakanın bildirildiği 11 Mart 2020'den günümüze yaklaşık yirmi ay geçmiş ve vaka sayısı 267,9 milyona, toplam ölümler 5,3 milyona ulaşmıştır (WHO, 2021). Koronavirüs Pandemisi hayatımızı, ekonomimizi ve dünyanın neredeyse her köşesini etkilemiş ve ülkelerin tarihindeki en ölümcül salgınlardan birisi (The New York Times, 2021) haline gelmiş; yoğun nüfus ve yüz yüze ilişkilerden kaçınılamayan ekonomik sosyal yapılarıyla kentsel alanlar, pandeminin en yüksek sayı ve oranda etkilediği alanlar olmuştur. Kent planlamanın tarihsel kökeni sağlıklı yaşama talebiyle doğrudan ilişkilidir ve planlamanın, tasarımın, mimarinin kodlarının oluşmasında önemli etkilerde bulunmuştur. Kentlerin daha sağlıklı yaşama yönelik yapılaşmasının ve donatılarla geliştirilmesinin yolunu çoğunlukla bu türden büyük etkisi olan salgın (veba ve diğer bulaşıcı hastalıklar) hastalıklar açmıştır.

Tarihsel olarak, hastalıklar kentlerin şekillenmesinde önemli rollere sahip olmuştur (Sennett, 2018). 14. yüzyıldaki veba salgınıyla, şehirlerde atık su boruları, bina temelleri, çatı saçakları ve kapı eşikleri gibiçok sayıda alt yapı ve yapı boyutunda değişikliğin hayata geçirilmesi; 19. yüzyıldaki kolera salg1nıyla, sağlık öncelikli çalışmalara bağlı olarak kent yönetimi ve şehir planlamanın disipliner çalışmalara dönüşmesi ; tüberkülozun önlenmesi için konutun havadarlık ve güneş hakkı standartları ile kodlanması; 20.yüzyılda sanayileşme ile göçlerin artması sonucu kentlerde gecekondulaşmanın yol açtığı sağlık sorunlarına bağlı çıkartılan konut yasaları; demiryolu ve otomobil üretimi ve nihayetinde son yıllarda dijitalleşme ile gelen akıllı kent uygulamalarının etkisi şehirlerin planlanmasında ve yenilenmesinde rol almıştır (Berg, 2020; Oflaz, 2020; Özüduru, 2020). Bu çerçeveden bakıldığında, kent formları insanların sağlığında önemli rol oynasa da (Bitkovitz, 2019) salgın hastalıkların merkeze kamu sağlığını koyarak yolları, binaları, meydanları yani müşterek mekanları olumlu ya da olumsuz olarak biçimlendirdiğini söyleyerek, Klaus (2020)'nin "hastalık kentleri şekillendirir" sözünü desteklemek yanlış olmayacaktır. Kimmelman (2020), insanların bir arada olma duygusunu ve sosyalleşmesini yaraladığı için pek çok pandemiyi "kent karşıtı" olarak tanımlasa da, bu karşıtlıklar ve şekillendirmeler kentlerin nasıl planlanması gerektiği ve hatta mevcut ve gelecekteki krizlere nasıl daha iyi tepki verebilecekleri konusunda yeni gelişmelerin yolunu açıcı tartışmalara neden olmaktadır. Yaşamakta olduğumuz 21. yüzyılın ilk çeyreğinde tüm dünyayı sosyoekonomik olarak etkisi altına alan Covid-19 Pandemisi, yaşanılan kentlerin 
de mercek altına alınmasını sağlamış; pandemi sürecinde yapılan çalışmaların bulguları, salgınların şehrin büyüklük, kentsel yoğunluk, kendi kendine yeterlilik, toplu taşıma kullanımı, açık alan sağlama ve konut tasarımı ve gelecek için daha iyi planlamaya yönelik yeniden gözden geçirilmesini gerektirdiğini ortaya koymuştur (Bolleter, vd., 2021).

Covid-19 hastalığına yol açan virüsün yüksek bulaş riski nedeniyle uygulamaya konulan sokağa çıkma kısıtlamaları, insanların günlük gereksinimlerini yürüme mesafesindeki hizmet ve donatı alanlarından karşılamak zorunda kalmasına ve yaşamın konut alanı ve yakın çevresinin sınırlarına çekilmesine neden olmuştur. Yürüme ve yürünebilirlik önem kazanmış, kentsel hareketlilik yaşanılan mahalle ile sınırlanmıştır. Bu durum, kaçınılmaz olarak mahalle ve mahalle-sokak kurgusunun sorgulanmasını, mahalle ölçeğinde sosyal donatılara erişilebilirliği ve yürünebilir sokakları tekrar planlama gündemine taşımıştır. Erişilebilir mesafelerde temel ihtiyaçları planlamak gerekliliğinin yanında su, gıda, barınma, sağlık hizmetlerine erişimin salgın hastalıklarla mücadelede önemi bir kez daha görülmüştür. Hastaneler, üniversiteler, otogarlar gibi büyük yapıları kentin dışına taşıyıp insanları oraya ulaştırmaya çalışmak yerine, erişilebilir mesafelerde daha küçük alt birimler oluşturarak erişilebilirliğin sağlanmasının daha doğru (Oflaz, 2020) olduğu gözlemlenmektedir. Bu gözlemler Ersoy (2015:105)'in belirttiği olası bir durumda ilk müdahaleyi yapabilecek sağlık kurumlarının mahalle ölçeğinde yer alması; ilk müdahale yapıldıktan ve/veya tanı koyulduktan sonra üst kademe sağlık merkezlerine gönderilmesi gerektiği görüşünü desteklemektedir.

Ayrıca yaşanan pandemi süreci, sokakların fiziksel altyapı olmasının yanında karantina ve sosyal mesafe için alınan önlemler nedeniyle sosyal yaşam, boş zaman değerlendirme ve rekreasyon amaçlı kullanımının ne kadar önemli olduğunu göstermiştir. Kısacası, komşularımızla karşılaştığımız sokaklar aslında sosyal altyapının da bir parçasıdır (Glover, 2020). Pandemi döneminde mahalle sınırları içindeki özel mülkiyete konu olmayan çok sayıda çıkmaz sokak, otopark, araba geçmeyen cadde ve kaldırım birer etkinlik mekânına, sosyal mesafe içerisinde komşular ile temas ve dayanışma alanlarına kendiliğinden dönüşmüştür (Mehta, 2020).

Pandemi krizinde ortaya çıkan bu deneyimler, planclara ve yerel politikacılara mahalle, erişilebilir donatılar ve yürünebilir sokaklara duyulan ihtiyacı göstermesi açısından önem taşımaktadır. Bu çalışma, Pandemi döneminde mahalle kurgusunu, sosyal donatıların erişilebilirliğini ve yürünebilir sokakların gerekliliğini, sağladıkları yararlarla ilişkili olarak ele almakta, bu 
ilkelerle planlanan mahallelerin yaşanabilir ve dirençli kentlerin oluşmasındaki önemini ortaya koymaktadır.

Çalışmada öncelikle Covid-19 Pandemisi ve mahalleye ilişkin yapılan literatür taramasına yer verilmiştir. Mahalle kavramı, pandemi ile birlikte önemi artan donatı alanlarına erişilebilirlik ve yürünebilir sokaklar açısından irdelenmiştir. Çalışmanın odak noktası olan bölümde Covid-19 salgın süreciyle beraber mahalle donatılarının erişilebilirlikleri ile birçok ihtiyacın mahalle içinde karşılanması ve daha esnek, geçici kullanımlara da olanak sağlayan bir çerçevede ele alınması gerekliliği nedeniyle, mahalle kavramının ve sokakların kent planlama süreci içinde geçirdiği değişim, birlikte ele alınmıştır.

\section{Yöntem}

Yerleşim alanlarındaki sakinlerin açık ve kapalı alanlardaki sosyal faaliyetleri için donatıların sağlanması ve bunlara erişilebilmesi gerekmektedir. Bu ihtiyaçların standart sağlıklı kentliler ile yaşlı, öğrenci, hasta, hamile, fiziksel engelli ve diğer dezavantajlı kentlilerin erişebileceği şekilde konumlanması, sürdürülebilir sosyal ve fiziksel iletişim için önemlidir. Bir mahallenin erişilebilirlik derecesi, sakinlerinin hareketliliğini büyük ölçüde etkiler, başka bir deyişle, ne kadar özgürce hareket edeceklerini belirler (Ioannou, 2019).

Çalışma bir derleme niteliğindedir ve alanyazın taraması ile seçilen anahtar sözcükler üzerinden konuyla ilgili araştırmaları sistematik bir şekilde değerlendirmektedir. Scopus, ve Web of Science (WOS) veri tabanlarında yapılan taramalar anahtar sözcükler ve özetler üzerinden yapılan değerlendirmelere göre sinıflandırılmıştır.

Scopus ve Web of Science veri tabanlarında Temmuz 2021'de gerçekleştirilen çalışma ile "komşuluk birimi / mahalle, erişilebilirlik, sokak, tasarım, yapı, pandemi, Covid-19, şehir planlama, yürünebilirlik" kavramları taranmıştır (bkz. Şekil 1). Buna göre, "ulaşım, erişilebilirlik ve sokak" anahtar sözcüklerini içeren çalışmaların mahalle ölçeğindeki tartışmaların odağını oluşturduğu görülmektedir. Bir diğer belirgin sonuç ise, Covid-19 Pandemisi, 2020-2021 yıllarında "sokak" konusundaki araştırmaların sayısını artırmıştır. Taramaya ilişkin detaylı analiz tablosu Ek-1 olarak çalışmanın sonunda sunulmuştur. 


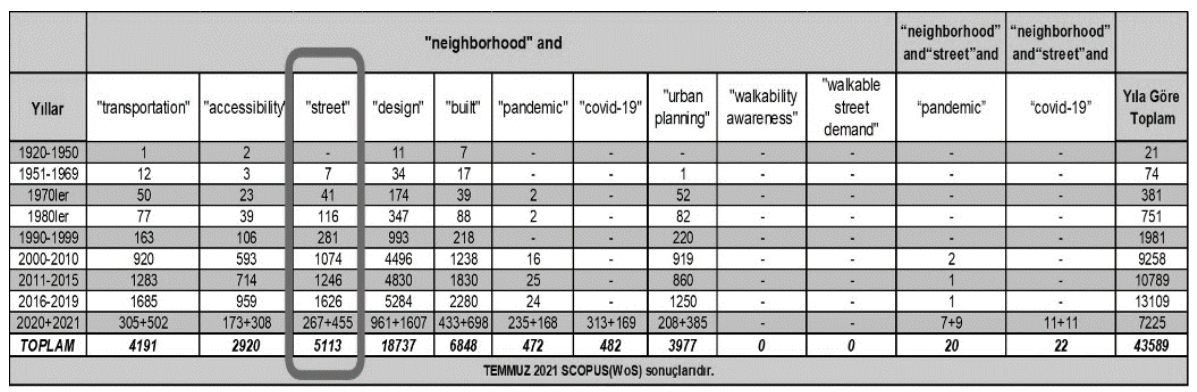

Şekil 1. Scopus ve WoS veri tabanlarında 1920-2021 yılları için "mahalle ve ulaşım, erişilebilirlik, sokak, tasarım, yapı, pandemi, şehir planlama, yürünebilir sokak talebi anahtar sözcüklerini içeren "mahalle" ve "sokak" ve "pandemi"yi içeren; "mahalle" ve "sokak" ve

"Covid-19'"u içeren çalışmaların dağılımı (Yazarlar, 2021)

\section{0 Öncesi Çalışmalar}

Ek-1 incelendiğinde çeşitli planlama yaklaşımlarını ele alan; 19. yüzyıldan günümüze kadar mahalle planlamasında sokak kurgusu ve erişilebilirliği anlatan, erişilebilirlik, standart mesafe, müşterek, fiziksel aktivite gibi ulaşım ve komşuluk kavramlarını barındıran, sosyal ilişkileri anketlerle analiz eden ve hem sosyal hem de mekânsal sürdürülebilirliği bağdaştıran çalışmalar yer almaktadır.

Bahçe kent, komşuluk birimi tasarımının bir ilkokul çerçevesinde şekillendirilmesiyle başlayan literatürdeki ilk çalışmadır ve 19. yüzyılın son yıllarına kadar gitmektedir (Howard, 1898). Perry 1929'daki çalışması ile komşuluk birimi kavramının güçlü ve zayıf yönlerini tespit ederek, kendisinden sonra gelen tasarımlarda yürüme mesafesinin önemli etken olmasında yol göstermiştir.

Rosin (1998), sokakları kişinin iç dünyası dışındaki alanları deneyimlediği, komşu ve toplumla kaynakları paylaştığı, kamusal alanda davranışla ilgili kavramların ve fikirlerin sosyalleştiği ve yeni bir nesle iletildiği yer olarak ele almış ve "Street As Commons - Müşterek Sokak" kavramını kullanmıştır. Epstein (2002), halka açık alanlardaki araç park yerleriyle mahalleye ait bir sokakta park ilişkisini, yerel sokakların kamusal ortak alanlar olmasını ve mahalle sakinlerinin ortak alanı olan sokakların ticari alanlarla aynı araç park yerlerini paylaşmaları durumunu incelemiştir.

\section{0-2010 Arası Çalışmalar}

2000'li yıllara yaklaşılmasıyla beraber tüm sokak kullanıcıları için komşu ya da uzak hedeflere erişim sağlama birincil işlevine ek olarak, konutla bağlantılı sokakların genellikle yerel sakinlerin toplanabildiği alanlar olarak kullanılmasıyla daha güvenli ve daha yaşanabilir mahalleler yaratma yönündeki 
işlevi üzerine araştırmalar geliştirilmiştir. Teknolojinin gelişmesiyle yaşanan çevresel kirlenmeye bağlı olarak sürdürülebilir planlamalar içerisinde yürünebilen, erişilebilen ve karma kullanıma sahip mahalle tasarımları ve sokak dokuları ile bağlantıları üzerinde yoğunlaşılmıştır. Frischmann (2005) "altyapı müşterekleri” terimini geliştirerek insanlar tarafından yine kamu için geliştirilen fiziksel sistemleri bu kavram içerisinde değerlendirmiş; ticaret, iletişim ve rekreasyon işlevlerini içeren, çalışanların hareketliliğine yönelik yol sistemlerinin sosyal fayda sağladığını ve altyapı müştereklerinin kaynaklarının kullanıcı kitle tarafından açıç̧a erişilebilir olması gerektiğini vurgulamıştır. Mahalleler kullanıcılarının, mahallenin sunduğu tüm değer ve hizmetlere ulaşabilmesiyle "müşterekleşebilir." Erişilebilirliğin bu bağlamda tanımı da ayrı bir önem kazanmaktadır.

Erişilebilirlik kavramını, özellikle seyahat talebinin çok karmaşık olduğu kentsel alanlarda çözülmesine yönelik çabaların araştırmalara konu olmasıyla beraber, mahalle ortamıla ilgili bazı algıların çeşitli fiziksel aktivite alanları ile ilişkileri, yetişkinlerin hedeflere yürüme ve yürümenin diğer fiziksel aktivitelerle olan ilişkileri de araştırma konusu olmuştur (Saelens, Sallis, Frank lens, 2003). Sonuçlar, hem yetişkinlerde hem de gençlerde sosyal tesislere erişim algısının yüksekliği ile boş zaman aktivitelerinin artması arasında olumlu bağlantılar tespit edilmiştir. Yine Lund (2002), Rogers ve Sukolratanametee (2009)'un yaptığı çalışmalarda çekici, erişilebilir, bağlantılı, karma, yürünebilir ve yeşil sokakları yaya dostu olarak tanımlayarak, böyle bağlantıların daha fazla sosyal etkileşim şansına yol açtığını ve topluluk hissine katkıda bulunduğunu belirtmiştir. "Yürünebilirliği artıran mahalle kurgusu"nun nasıl olması gerektiğine ve sosyal donatıların mahalledeki yer seçimiyle bağlantılı erişilebilirliklerine yönelik çalışmalar, sokakları bu hedeflere göre şekillendirmeyi hedeflemektedir. Halk katılımını da destekleyen bu akımda, tüm grupların hayata tutunmasında ruhsal yönleri de gündeme alarak, sosyo-fiziksel entegrasyonla üretken mahalleler geliştirilmesi talep etmektedir.

\section{Sonrası Çalışmalar}

Son on yıldaki araştırmalara bakıldığında ise kamu alanları ve ulaşım konuları dikkate alınarak toplu taşıma politikaları, yayalaştırma ve yaşam kalitesi konularının önemi artmıştır. Son iki yılda ise pandemi kriziyle toplu taşımadan uzaklaşan ve mahallesiyle baş başa kalan insan yaşamlarında yürünebilirliğe ve halk sağlığına vurgu yapan araştırma ve yayınlar artmıştır. 
Günümüzde engelli, yaşlı, çocuk da dahil tüm kişilerin diğer herkes gibi her yere, kendilerini farklı hissetmeden ulaşabilmesi için ve Pandemi ile gelen "Evde Kal!..." çağrısıyla kapanılan ev ortamı nedeniyle ortaya çıan hareketsizlik artışı da göz önüne alındığında yürümeyi, fiziksel aktiviteleri, insanların sosyalleşmesini destekleyen her türlü çalışma önemli bir yer tutmaktadır. Planlamacılar, tasarımcılar, mimarlar, peyzaj yöneticileri ve medya bu krizin kamusal alanları ve sosyal ilişkileri nasıl dönüştüreceğini araştırmaktadır (Alter, 2020; Roberts, 2020; Van der Berg, 2020). Sokakların doğru kurgulanarak, tüm grupları yürümeye teşvik etmesi, üşendirmemesi, korkutmaması, açık alanlarda aktivitelere yöneltmesi için çalışmalar, yeri geldiğinde anketlerle devam etmektedir (Kerr vd. 2011; Nathan, Wood, ve Giles-Corti, 2014; Cerin vd., 2016; Timmermans vd., 2016). Yaşlı yetişkinler için parklara ve çeşitli park tesislerine bağlanabilirliğin önemli olduğu bulguları mevcuttur (Park ve Roger, 2020). Mahallenin erişilebilirliği ve donatılarının çeşitliliği yanında yeşil alana ağırlık veren, otomobile uzak duran kurguların araştırmaları ve de sosyalleşmede mahallenin değerini gösteren çalışmalar yapılmaktadır (Akcan, 2020; Glover, 2020; Gray, 2020; Honey-Roses vd. 2020; Mehta,2020; Tamborrino, 2020; Ülkeryıldız, Vural, Yıldız, 2020).

$\mathrm{Bu}$ bölüm değerlendirildiğinde ve alanyazına Covid-19 Pandemisi gündeminden bakıldığında, sağlıklı toplumlar için yaşanabilir çevreler yaratmaya yönelik ve kent planlama, tasarım ilkelerinin önemine vurgu yapan araştırmaların odağını, komşuluk birimi, erişilebilirlik ve yürünebilirlik kavramlarının oluşturduğu görülmektedir.

\section{Pandemi Sürecinde Mahallenin, Mahalle Ölçeğinde Planlamanın ve Tasarımının Artan Önemi}

Komşuluk birimi/ mahalle, kent için en temel mekânsal tasarım birimidir. Sağlıklı konut yaşam çevrelerinin oluşturularak yaşanabilir kentlerin yaratılmasının temel taşıdır. Keleş (2021) Kent Bilimleri Sözlüğü'nde komşuluk birimini "dar bir alanda yer alan, daha çok yüz yüze ve kişisel ilişkilerin egemen olduğu, üyeleri yürüme uzaklığı içindeki okul, oyun yeri, bakkal ve manav gibi ortak kent kolaylıklarından güçlük çekmeden yararlanabilen küçük yerleşme birimi" olarak tanımlamaktadır. Bu tanım temel sosyal ihtiyaçlara yürüyerek ulaşılabilecek yakınlık ile sınırlı coğrafi bir büyüklük ve yüz yüze ilişkiler ile etkileşim içinde bir topluluk tarif etmektedir.

Mahalleye ilişkin ilk planlama çalışmaları Ebenezer Howard'ın (1898) yerleşimleri bir ilkokul çerçevesinde şekillendirdiği "bahçe kent” kavramına ve 
uygulamasına kadar uzanmaktadır. Sonrasında, 1929'da Perry'nin geliştirdiği mahalle tasarımında, mahalle biriminin bir ilkokulun varlığına olanak sağlayacak nüfus hesabına dayandırılarak, merkezde bulunan bir okul için en fazla 400 metre veya 5 dakikalık bir yürüme yarıçapı hedefiyle, bu mesafenin ilkokul öğrencisi tarafından kolaylıkla yürüyebilmesi ilkesinin öne ç1karıldığı görülmektedir (Barlas, 2012). Komşuluk biriminde sokak ağının taşıdığı trafik yükü açısından kademelendirilmesi diğer önemli bir tasarım ilkesidir. Komşuluk birimi içinde gerekli olan hareketliliği ve donatılara erişimi sağlayan sokak genişliklerini (transit trafiğe izin vermeyen, taşıt hızı ve yoğunluğunu denetleyen bir sokak ağıyla) kademelendirerek, yaya ağırlıklı ve her türden kullanıcıya uygun güvenli bir kentsel hareketlilik sağlar.

Perry'nin ilkelerini Radburn'e uygulayan Stein ve Wright, yaya ile araç trafiğini tümüyle ayırıp, kesintisiz uzanan ortak yeşil alan etrafında ve çımaz sokaklardan oluşan konut kümelerini ve bunlara hizmet veren bir yerel sokak düzenini oluşturmuşlardır (Farr, 2008; Kılınçaslan, 2012).

Duany ve Plater-Zyberk (1994), Perry ile benzer şekilde komşuluk birimi kavramında beş dakikalık yürüme mesafesini, yaklaşık 400 metrelik yarıçapı ve merkezde toplu taşıma durakların, araç park yerlerini tanımlamışlardır. Çıkmaz sokaklara ise bir okulu ve birbirini kesen sokak ağı sistemi sürekliliğini kesintiye uğrattı̆̆ için yer verilmemesi gerektiğini belirtmişlerdir (Duany ve Plater-Zyberk 1994; Farr,2008).

Farr (2008) tarafından önerilen komşuluk biriminin yarıçapı yaklaşık 400500 metre arasında olup, merkezde bir okul şartı koymayarak, bir komşuluk biriminin içerisinde yaya ulaşım ağının bir parçası ve kamusal eğlence-dinlence amaçlarına hizmet eden açı/yeşil alan ekseni geliştirmiş ve yağmur bahçeleri önerileriyle sürdürülebilir uygulamayı hedeflemiştir (Calgary Regional Partnership, 2011).

Amerika Planlama Birliği'nin (American Planning Association) mahalle için geliştirdiği ilkeler ise, tarih boyunca farklı farklı tasarım kriterlerini içermekle beraber, sürdürülebilirlik kavramını da tanımlara dahil etmiştir. İklim değişikliğine bağlı taleplere cevap verebilen, yaya ve bisiklet kullanımı ağırlıklı erişimi kolay sokakları olan, insan ilişkilerini ve sosyal etkinlikleri destekleyen mahallelerin sürdürülebilir olduğu vurgulanmaktadır (American Planning Association, 2017).

Yukarıda belirtilen çalışmalarda, yürünebilir ve iyi bağlantılı sokakları olan, yaya ve bisiklet kullanımı ağırlıklı, kademeli bir yol ağı içeren ve taşıt trafiği sadece konuta erişimin gerektirdiği kadar olan, trafik yoğunluğunun yayayı rahatsız etmeyecek düzeyde olduğu (Perry, 1929; Kılınçaslan, 2012) 
ve sosyal etkinlikleri destekleyen eğitim, rekreasyon, sosyal tesis donatıları ile ticari birimlerin yürüyerek erişilebilir mesafelerde planlandığ 1 ve tasarlandığ (Gül, Sultan ve Jokhio, 2020) mahalle ölçeğinin önemi vurgulanmaktadır. Kademelenmenin insan psikolojisi ve "komşuluk anlayışı" üzerinde etkisini tespit için Donald Appleyard ve Mark Lintell(1971) San Fransisko'da bir anket çalışması yapmışlardır. Bu araştırma, konut yaşam kalitesiyle trafik yoğunluğunun ters orantılı olduğunu, transit trafiğin "yaşanabilir çevre" yi ne kadar olumsuz etkilediğini ortaya koymakta; aynı zamanda, yoğun trafikten koruyan önlemlerin alınmasının mahallenin güçlü bir kimlik ve sakin çevre kazanmasına yardımcı olacağını göstermektedir. Bu nedenle, bölge kimliğinin bozulmaması için yol kademelenmelerinin oluşturulması ve mahalle çevresinden geçmesi gerekmektedir (Appleyard ve Lintell,1971).

Günümüzde küreselleşme, modernleşme ve bireyselleşmenin yaygınlaşması ile komşuluk ilişkilerinin kaybolması; yüz yüze insan ilişkileri ile insanlar arasındaki yardımlaşma, dayanışma duygularının azalması; mahallede bir zamanlar var olduğu söylenen sosyal ağların güçlü olduğu yaşam biçimi gibi tüm değerlerin ortadan kalkması sonucunu doğurduğu, mahallelerin sonunu getirdiği tartışılırken (Bıçkı, 2019; Ökten, 2014); Covid-19 salgınıyla birlikte kaybolmaya yüz tutan bu değerler pandemi döneminde evde kalan halkın sosyalleşme ihtiyacını en yakınındakiyle karşılaması sonrasında, tekrar önem kazanmaya başlamıştır. Böylece, komşuluk ilişkileri, "yeni normal" sürecinde sosyal mesafe kurallarına uygun olarak mahallelerde, uzak veya yakın mesafelerde, balkonlarda, apartman bahçelerinde, sokaklarda yeniden kurulmaktadır.

Fiziksel temas ve insan yoğunluğunun virüsün yayılmasında etkili olması nedeniyle, Türkiye dahil pek çok Avrupa ülkesinde kamusal alanlara kullanım kısıtlaması ve kişi sayısı sınırlandırılması getirilmiştir. Hatta evde kalınması zorunlu tutularak uzun süreli karantina uygulamaları yapılmıştır. $\mathrm{Bu}$ süreçte okullar, kütüphaneler, sinema ve spor salonları, alışveriş merkezleri, restoranlar ve benzeri sosyo-kültürel ve ekonomik mekanlar/alanlar kapatılmıştır. İnsanların alışkanlıklarına uymayan "yeni normal" olarak adlandırılan bu dönemde ilişkilerin sosyal ve mekânsal olarak farklılaştı̆̆ görülmektedir. "Yeni normal" dönemde, çeşitli kısıtlamalar insanların açık alan arzusunu azaltmadığı gibi aksine artırmış ve ihtiyaçlarını karşılama sürecinde ortak alanlarda ilginç uygulamalar deneyimlemelerini sağlamıştır. Sosyal Mesafe (Social-Distance) şartının, modern dünyanın getirdiği "kalabalık içindeki yalnızlık" duygusunu arttırabileceği endişesiyle, insanlar yeşil ile bütünleşme, suyu görme, oyun oynama, yürüme, spor yapma gibi aktivitelerini, 
sosyal mesafenin sağlanabileceği en yakınındaki açık alanlara ve hatta sokaklara taşımıştır. Bu süreçte, çok işlevli ve yaratıcı uygulamalar insanların gerek konutlarında gerekse ortak kullanım alanlarında izlenebilmektedir. Kişilerin özel alanı ile sokağı arasında bir filtre görevi gören balkonu, terası ve pencereleri sosyalleşme için kullandığı (Tamborrino, 2020), açık ve yeşil alanlarda ise geçici ve esnek kullanımların (yerel gazete ve yiyecek alanları açmak, sanatsal aktiviteler düzenlemek vb.) söz konusu olduğu görülmektedir.
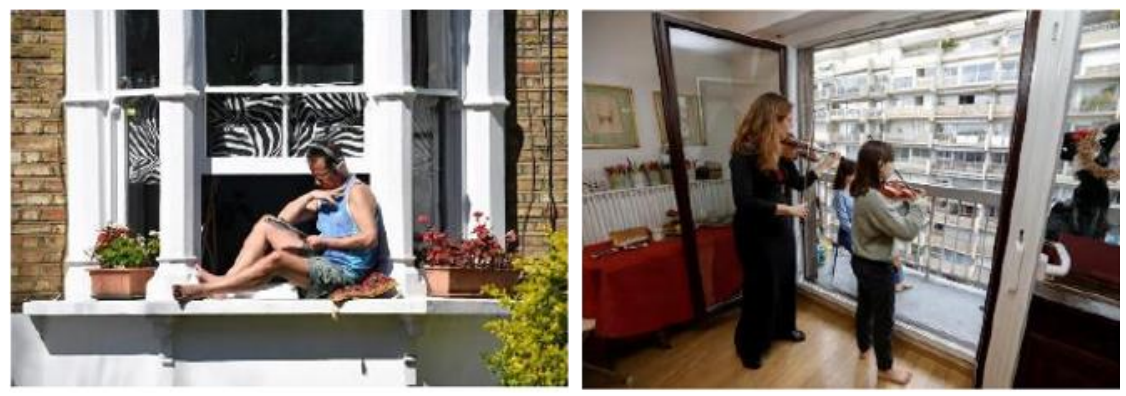

Şekil 2. Teras ve balkonların sosyalleşme alanı olarak kullanılması (Kaynak: Reuters, 2020)

Tam da bu noktada, kentlerin günümüz koşullarında tarım, trafik, eğitim gibi pek çok alanda insanın en büyük destekçisi olan teknolojik uygulamalar, COVID-19 salgını boyunca farklı bir boyutta yaygınlaşmıştır. Çin, virüsün yayılmasını takip etmek için akıllı telefon uygulamaları kullanmış (Elegant ve Chandler, 2020), Rusya kısıtlamalara uymayan insanları izlemek için bir yüz tanıma sistemi geliştirmiştir (Ball, 2020). Hindistan drone ile kalabalık toplulukları izleyerek vücut sıcaklıklarını ölçmüş (Poovanna, 2020), Güney Kore karantinadan insanların kaçmaması için bileklikler kullanmıştır (Cole, 2020). Bu kapsamda hastalığa yakalananların bilinmesi ve risk bölgelerinin tespiti için Türkiye'de de Hayat Eve Sığar (HES) uygulaması hayata geçirilmiştir. Yaşam birimlerinde bazı alanların ev-ofis (home-office) (Akcan, 2020) olarak kullanılmasına yol açan uygulamalarla birlikte, mahallesinin donatılarına telefon uygulamaları ile bakan insanların sayılarının da artmasıyla beraber teknolojiye olan ihtiyaç da yüksek seviyelere ulaşmıştır. Coğrafi bilgi sistemleri (GIS) ve kentlerin dijital altyapılarına yapılan yatırımlar bu dönemde artmış ve halen de arttırılmasına gerek duyulmaktadır.

\section{Pandemi Koşullarında Yürünebilir Sokaklar ve Sosyalleşme}

Pandemi nedeniyle sınırlanan hareketlilik döneminde bireylerin uzak mesafelere gitmeden yürümesine, bisiklet kullanmasına, fiziksel aktivitelere ka- 
tılmasına ve diğerleriyle sosyalleşmesine katkısı göz önüne alındığında, mahalle ölçeği ve sokak alanları öne çıkmaktadır. Ancak, Covid-19 salgın süreciyle beraber diğer kamusal alanlarda olduğu gibi sokaklarda da sosyal mesafenin sağlanması önem taşımaktadır. Hall (1996), insanlar arasındaki mesafeyi dört ölçekte ele almakta (samimi mesafe ( 0.45 metreden az), kişisel mesafe (0.45-1.2 metre), sosyal mesafe (1.2-3.6 metre), halka açlk mesafe (3.6-7.5 metre ve daha fazlası)) ve bu ölçeklerin insanlar arasında farklı duyusal alg1lara yol açtığını belirtmektedir [Hall (1996)'ya atfen Mehta (2020)]. Özellikle Covid-19 salgın süreciyle beraber kamusal alanlarda sosyal mesafenin sağlanması oldukça zor hale gelmesine karşın, sokak alanlarında pek çok mahallede sosyal mesafe / uzaklık önlemi, yaratıc yeni sosyalleşme olanakları için kullanılmıştır (Mehta, 2020). Pandemi öncesinde sosyal etkileşim alanı olmaktan büyük ölçüde çıkan ve araçlara terk edilen sokakların tekrar yaya ve sosyal etkileşim için kazanılmasında pandemi süreci önemli bir fırsat oluşturmuştur.
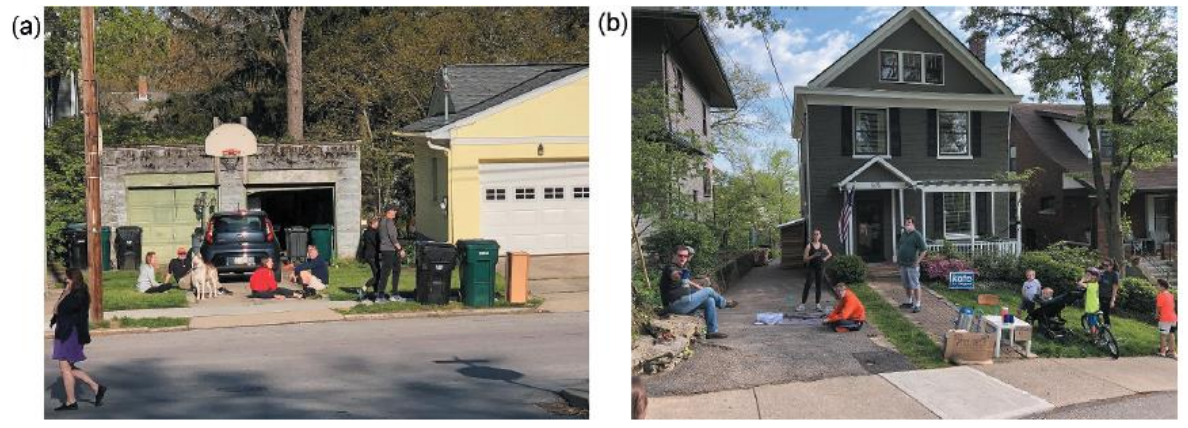

Şekil 3. Sokak ve bahçelerin sosyal alana dönüştürülmesi (Kaynak: Mehta, 2020).

Mahallede fiziksel aktivite ve hareketliliği destekleyen ortak alanlara duyulan gereksinim, pandemi döneminde halk sağlığının korunmasında mekân planlaması ve tasarımı ile uğraşan disiplinlerin önemini (Erdoğanaras, Cihangir-Çamur, Görer-Tamer ve Mercan, 2020) görünür kılmıştır. Mahalle, sokaklar ve kaldırımları birer sosyal altyapı, mahalle sakinlerinin gereksinimlerine yönelik olarak şekillendirilen fiziksel donatılar olarak kabul ettiğimizde, sokağın bir sosyalleşme alanı olarak yeniden planlanmasının ve tasarımının günlük yaşama yapacağı olumlu katkısı (Glover, 2020) kendiliğinden ortaya çıkmaktadır. Ayrıca sokaklar sosyal donatılara olduğu gibi doğaya ve diğer açı alanlara erişimi sağlayan kamusal izlerdir. Corraliza (2000)'ye göre sokaklar, diğer insanlarla ve çevreyle etkileşim kurmak için parklara ek olarak farklı firsatlar da içermektedir. 
Covid-19'un yayılmasını önlemek için uygulanan hareketlilik kısıtlamalarıyla toplu taşıma sistemlerinin kullanımında ortaya çıan düşüşler, bir yandan da olumlu gelişmelere yol açmıştır. "Paylaşımlı sokaklar ve sakin sokaklar" gibi uygulamaların yaygınlaştırılması, sokaklarda ve caddelerde yürüyüş ve bisiklet kullanımının artş̧ını desteklemiştir (Sharifi ve KhavarianGarmsir, 2020). "Yaya Öncelikli Sokaklar" veya "Yaşayan Sokaklar" (home zone, woonerf) olarak tanımlanan "Paylaşımlı Sokaklar Uygulaması" ve Latin Amerika'da "Ciclovias Recreativas - Ana Caddelerin Trafiğe Kapatılması Etkinliği" gibi sürdürülebilir bir yaşam için pandemiden önce sesini yeterince duyuramamış çalışmalar, bir anda en gözde ve sıkça uygulanan politikalar olmuşlardır.

Herkesin ortak kullanımı için yollar taşıt trafiğinden arındırılarak yayalaştırılmakta ve kullanıcılar arasında farkındalık yaratmak için yer düzleminde güvenli hareket alanı oluşturulmaktadır. İyi bir sokak peyzajı mahalle sakinlerinin çevresine ve komşusuna iyi bağlanmasını, aktif sosyalleşmeyi ve topluluk hissini desteklemektedir (Abass, Andrewsc ve Tuckera, 2020). Ortak kullanıma uygun alanlar taşıttan arındırılarak, yalnızca bisiklet sürüşü, kaykay, yürüyüş, koşu ve benzeri yaya aktivitelerine izin verilmekte, hafta sonlarında daha çok açık alana çıkış ile sosyalleşme hedeflenmektedir.

Kuzey Amerika Kentsel Ulaşım Yetkilileri Birliği'nin (NACTO) bir programı olan Küresel Kentleri Tasarlama Girişimi (GDCI), hazırladığı "Pandemi Müdahalesi ve Toparlanma Sırasında Sokaklar Rehberi"ni tüm dünyadan şehirlerin geliştirdikleri sokak dönüşümü projelerini içerecek şekilde Mayıs 2020 'de yayınlamıştır. Milano, Bogota, Amsterdam, Auckland gibi şehirlerin bu kriz döneminde yaptığı bariyerlerle hız azaltma yönetimi, kaldırım genişletmeleri, güvenli yaya geçitleri, yavaşlatılmış sokaklar, halka açık/oyun sokakları, bisiklet yolları, toplu taşıma şeritleri/durakları ve erişim, teslimat alanları, açık havada yemek yeme alanları, açık hava pazarları, sokakların protestolar için ayarlanması gibi etkinliklerin düzenlenmesi, sosyal etkileşimde sokak ve mahalle kurgusunun değerini ortaya koymaktadır. Sokaklar, tüm mahalle kullanıcılarının, mahallenin sunduğu tüm değer ve hizmetlere eşit ulaştırdığ ölçüde müşterektir ve yüksek mekânsal bütünleşme, çeşitli etnik ve kültürel grupların sosyal bütünleşmesini teşvik etmektedir. Böylece, bu tür mekânsal özelliklere sahip mahalleler, güçlü kültürel değerlerin korunmasına da katkıda bulunmaktadır. 


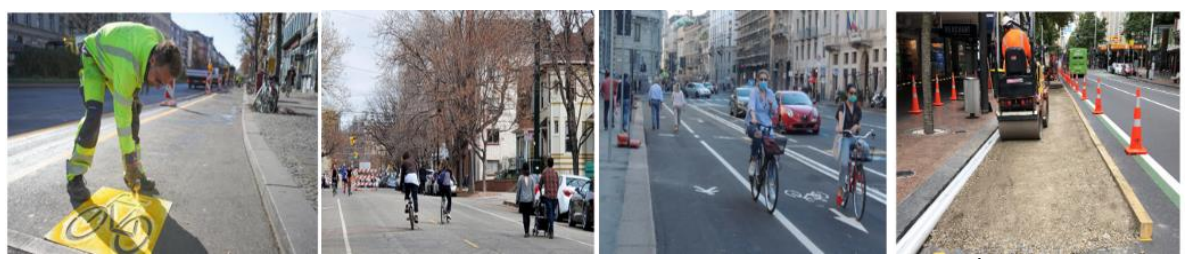

Şekil 4. Soldan sağa doğru Berlin(Almanya), Denver(ABD, Milano(İtalya) ve Auckland(Yeni Zelanda) şehirlerinde yapılan yayalaştırma ve bisiklet alanları tasarımları

(Kaynak: National Association of City Transportation (NACTO) Officials \& Global Designing Cities (GDCI) Initiative, 2020).

Mahalle sakinlerinin zaman geçirmek için mahalle içlerinde daha önce farkında olmadığı parkları keşfetmesine de vesile olan bu süreç, insanlardaki yürünebilirlik algısını da değiştirmektedir. İnsanlar eskiden arabayla gittiği marketlere şimdi yürüyüş ve hava alma gerekçesiyle de yürüyerek gidip gelmekte ve böylece yürünebilir uzaklık algısı genişlemektedir. Sahip olduğu donatıları bu anlamda yeterli olan ve kişilerin aktivitelerini destekleyen "yürünebilir mahalleler", pandemide insanların yaşamla ilişkisini korumasına, geliştirmesine destek vermektedir.

Yalnızca yaşam tarzını değiştirmekle kalmayan Covid-19 Pandemisi, bütün planlamacılara tasarım anlamında büyük bir deneyim de sağlamaktadır. Dikey mimarinin ve plansız kentsel yayılmanın aslında bir de arka yüzü olduğunu ve mahallenin ve donatıların insan hayatındaki vazgeçilmez yerinin göstermektedir.

Aslında pandemi sonrası üzerinde daha çok yoğunlaşılan uygulamalar olan daha yeşil şehir ve özgür sokak alanı oluşturmak, düşük karbon ekonomisi ve insanların ulaşım modu olarak yürüme ve bisikleti kullanması (Nieuwenhuijsen, 2020; Roberts, 2020) için verilen çabalara da destek verilerek insanların yakın çevrelerini kullanması teşvik edilmiştir. Bu potansiyel ulaşım modu değişikliğinin trafik sıkışıklığını hafifleterek, bireylerin fiziksel aktivitelerini arttıracağı ve sera gazı emisyonlarını azaltacağı öngörülmektedir (Aftabuzzaman, Currie ve Sarvi, 2010; Rabl ve De Nazelle, 2012; RojasRueda, de Nazelle, Teixidó, Nieuwenhuijsen, 2012). Geçici yol kapanmalar1nın, insanların yıllardır talep ettiği yayalaştırma ve kamusal alan geliştirme konusunda projelere girişmek için bir katalizör görevi göreceği ifade edilmektedir (Bliss, 2020). 


\section{Pandemi Koşullarında Erişilebilirlik ve Topluluk Dayanışması}

Erişilebilirlik, arzu edilen kullanımlara erişim kolaylığı olarak tanımlanmaktadır. Primerano (2003) erişilebilirliği “belirli yerlerden gelen kişilerin belirli bir zamanda bir ulaşım modunu kullanarak bir varış noktasındaki faaliyetlere katılmak için seyahat edebilme kolaylığı" olarak tanımlamıştır.

Çeşitli kısıtlamalarla hareketsizliğin arttı̆̆ Covid-19 Pandemisi döneminde yerel çevrede ihtiyaç duyulan hizmet ve donatılara herkesin eşit olarak ulaşmasını sağlamak büyük önem taşımaktadır. Covid-19 salgınından önceki pandemilerle ilgili kentsel araştırmaların temel olarak yoksul ve marjinalleştirilmiş grupları pandemilere karşı daha savunmasız hale getiren eşitsizlikler gibi konulara odaklandığı vurgulanmaktadır (Wade, 2020). Bu pandemi süreci de benzer şekilde toplumda var olan eşitsizlikleri daha da açık hale getirmekte, ortaya çikarmaktadır.

Kamusal açık alanlarda sosyalleşebilme, parklara erişebilme gibi donatılara, firsatlara en çok ihtiyaç duyan kişiler (çocuklar, yaşlılar, engelliler, işsizler) yaş, ekonomik durum, ulaşım eksikliği vb. nedenlerden dolayı özgürce hareket edemeyen kişiler olduğundan (Thompson, 2002), toplumda bu kesimlerin maruz kaldığı sosyal ve fiziksel engellerin ortadan kaldırılması gerekir. Bu dönemde her kesimden insanın her yere, kendilerini farklı hissetmeden ulaşabilmesi için yürümeyi, fiziksel aktiviteleri, donatılara erişimi ve dolayısıyla insanların sosyalleşmesini destekleyen çalışmalar önemli bir yer tutmaktadir.

Pandemi sürecinde en fazla gündeme gelen konu başlıklarından birisi de, tüm şehirlerin, sağlık hizmetleri, eğitim ve gıda gibi temel ihtiyaçlara otomobile ihtiyaç duymadan erişim sağlama hedefine yönelik olarak planlanmasıdır. Bu çerçevede pandemi sürecinin başlarında bisiklet şeritleri gibi sokak izi değişiklikleri, Barselona dahil olmak üzere birçok Avrupa kentinde "15 dakikalık şehir" olarak tanımlanan kentsel planlama fikrini cesaretlendirmiştir. Ancak eleştirmenler, konseptin Kuzey Amerika bağlamına iyi uyum sağlamayabileceği konusunda uyarmaktadır. Jay Pitter (Bloomberg Philanthropies ve Aspen Enstitüsü'nün ev sahipliğini yaptığı) CityLab-2021 konferansında, 15 dakikalık şehir konseptine karşı olduğunu belirtmiştir. Jay Pitter, şehirlerin, ırk ve sınıflar arasında tamponlar yaratmak için tasarlandığını ve bu önerinin, insanlar arasındaki toplumsal bölünmeleri somutlaştıran yüzyıllık planlama müdahalelerini tamamen görmezden geldiğini belirtmekte ve parklet veya bisiklet yollarının bu tür eşitsizlikleri gideremeyeceğini vurgulamaktadır. Ayrıca bu konseptin soylulaştırmayı teşvik edeceği düşünüldüğünden marjinal topluluklarda daha fazla yürünebilirlik veya bisiklet yolları 
gibi planlama ve tasarımlara karşı bir direniş olduğunu öne sürmektedir. 15 dakikalık şehir konseptinin yukarıdan aşağıya doğru bir yaklaşım olduğu için bu durumun işleri daha da kötüleştirebileceği belirtilmektedir. Başlangiç noktası olarak, sosyal ilişkilere sahip sokak ve mahalleleri yeniden tasarlamaya yönelik aşağıdan-yukarıya doğru tanımlanan süreçlerin, insanların tasarım konusunda kendi kararlarını vermelerine olanak tanıyan, sistematik, bütünsel ve yerel bir yaklaşımla ele alınmasının daha doğru olabileceği ve bu şekilde sosyal ve çevresel eşitsizliklerin önüne geçilebileceği vurgulanmaktadır (O'Sullivan, 2021).

Tüm mahalle kullanıcılarının, mahallenin sunduğu tüm değer ve hizmetlere eşit ulaştığ sosyal ve mekânsal bütünleşmesi sağlanabilecektir. Bu tür mekânsal özelliklere sahip doğru tasarıma ve bütünleşmeye sahip mahalleler, yaşanabilecek büyük siyasi, kültürel ve sosyal değişimleri (Toprak vd. 2019) beraberinde getiren küresel ölçekteki Pandemi krizini de daha rahat geçirebilecektir. Bu bağlamda, Covid-19 Pandemisi ortak kullanım ve donatı alanlarına eşit erişim sağlayan ve yürünebilirliği yüksek sokaklara sahip mahallelerin ne kadar değerli ve dirençli olduğunu göstermektedir.

\section{Sonuç}

Pandemi krizinde kazanılan deneyimler, planclara ve yerel politikacılara mahalle ölçeğinde hizmetlere ve donatılara erişim ve yürünebilir sokaklara duyulan ihtiyacı göstermesi açısından önem taşımaktadır. Bu çalışma, Pandemi döneminde mahalle kurgusunu, sosyal donatılarının erişilebilirliğini ve yürünebilir sokakların gerekliliğini halk sağlı̆̆ı açısından sağladıkları yararlar ile ilişkili olarak değerlendirmekte; mahalle/komşuluk birimi tasarım ilkelerinin yaşanabilir ve dirençli kentlerin oluşmasındaki rolünü ve önemini ortaya koymakta; mahalle/komşuluk ünitesi ve yakın çevrenin işlevsel tanımı yanı sıra kompozisyonu ve tasarımının pandemi koşullarında artan öneminin nedenlerinin ve yapılması gerekenlerin değerlendirilmesine yoğunlaşmaktadır.

Salgınların bağışıklık sistemi zayıf olanlarda daha tehlikeli etkilere yol açması, "bağışıklık sistemini güçlendirecek kentsel çevreler mümkün müdür?" konusunda önemli tartışmalara yol açmıştır. Bu kapsamda yapılan tartışmalarda, şehircilik yaklaşımı ile plancılara düşen rol ve sorumlulukların sadece salgınların etkilerini azaltmayı değil, oluşmalarını engellemeyi de hedefleyen farklı açlımlar gerektirdiğinin; bağışıklık sisteminin, yeme içme alışkanlıkla- 
rımız dışında stres yönetimi ve hareketli yaşam (egzersiz yapılan) çerçevesinde ele alındığında kentle ilgili bir konu haline geldiğinin; buna yönelik bir kentsel form için ideal başlangıç düzeyinin mahalle ve yürünebilir mahalle tasarımı olduğunun (Dursun, 2020) altı çizilmiştir.

Çevre dostu, birbiriyle bağlantıll, donatıları yeterli ve erişilebilir olan, yaya ve bisiklet öncelikli sokak kurgusuna sahip yaşam çevrelerine gösterilmesi gereken hassasiyet, Covid-19 Pandemisi'nde kendini bir kez daha göstermiştir. Evlerinden dışarıya çıkamayanlar ve çıktıklarında da ancak yürünebilir mesafelere gidebilen insanların mahalle içi aktivite günleri yaptığı, toplantılar düzenlediği ve sosyalleşme arzusunu kendi mahallesiyle ve sokağıyla karşıladığı kriz dönemi, yaşanabilir çevrelerin halk sağlığı açısından önemini ortaya koymaktadır. Teknolojideki ve halk sağlığındaki gelişmelere rağmen pandemiye dönüşmesi engellenemeyen Covid-19 hastalığı, merkezden yerele planlama, yönetim sistemleri ve mekanizmalarının beklenilen yanitı verememesinin temel nedenleri üzerinde düşünülmesine yol açmıştır. Salgının sosyal ve ekonomik yaşamı en çok etkileyen "tam kapanma, saat ve mesafe kısıtlamaları" mekânın oluşumunda iyi planlama süreçlerinin etkisinin her ölçekte sorgulanmasını gerekli kılmıştır (Daneshpour, 2020; O'Toole, 2020).

Sosyal etkileşime, yaratıcllığa olanak veren kamusal alanlar kentler için oldukça önemli mekânlardır. Pandemi süreciyle birlikte açık alanlara ve donatılara herkesin erişememesi veya herkes tarafından kullanılamaması gibi salgın sürecinden önce de var olan çoğu eşitsizliğin tekrar tartışıldığı görülmektedir. Özellikle parkların da kapalı olduğu süreçlerde insanlar sokakları yaşam mekânları haline getirmeye çalışmıştır.

Bu çalışmada incelenen alanyazında, Covid-19 Pandemi sürecinin plancı, tasarımc ve mimarlara özellikle insanın açı alan, yürüme, sosyalleşme, vb. gereksinimlerinin şehirciliğe entegrasyonunda önemli bir öğrenme firsatı sağladığı görülmüştür. Geleceğe yönelik olarak sokakların ve açık alanların insan odaklı tasarımına ilişkin cesaretlendirici kuramsal tartışmalar ve yeni uygulamalar sergilenmiştir.

Mahalle ölçeğinde yaşam çevrelerinin tasarlanması toplum sağlığı ve gönenci için önemlidir. Planlama, kentsel tasarım, peyzaj tasarımı, mimarlık, endüstri ürünleri tasarımı ve burada adını sayamadığımız ancak yaşadığımız çevreyi disiplinlerarası bir yaklaşımla üreten ve yaşanabilir kılma sorumluluğunu taşıyan tüm disiplinler "mahalleyi ve sokakları insanın sosyalleşmesini destekleyen, kolaylaştıran bir içerikle yeniden üretmenin, yürünebilir sokaklar ile sosyalleşmeyi sağlamanın önemini" Covid-19 Pandemisi sürecinde yeniden keşfetmiş görünmektedir. 


\section{Extended Abstract}

\section{An Insight to Walkable Streets and Accessibility of Neighbourhood Amenities during the Covid-19 Pandemic}

\author{
Kübra Cihangir Çamur \\ ORCID: 0000-0003-0343-3306 \\ Nilgün Görer Tamer \\ ORCID: 0000-0001-6502-3105
}

\author{
Fatma Erdoğanaras \\ ORCID: 0000-0002-0892-8431 \\ Gülsel Satoğlu \\ ORCID: 0000-0003-4601-2034
}

The literature review analysis presented in this paper takes into account the conceptual and practical change of neighborhoods and walkable streets during the Covid-19 Pandemic. About twenty-two months have passed since March 11, 2020, when COVID-19 was declared a pandemic by the World Health Organization (WHO) and the Coronavirus Pandemic has affected people's lives as well as national economies almost every corner of the world and has become one of the deadliest epidemics in the history of countries (The New York Times, 2021). Urban areas, with their dense populations and socio-economic structures where face-to-face relations cannot be avoided, have been the mostly affected areas by the pandemic.

The method of the article is review, and it systematically evaluates the researches on the subject through the keywords selected by the review of abstracts at first phase and detailed studies on selected articles. In July 2021, the Scopus and Web of Science databases were reviewed with the concepts of neighborhood unit/neighbourhood, accessibility, street, design, building, pandemic, Covid-19, urban planning, walkability" and or (see Figure 1). In the field of urban planning, there is a wide variety of publications on neighborhood, streets and other open-air activities especially for the last two years.

The historical origin of urban planning is directly related to the demand for healthy living, and diseases have played an important role in shaping cities and 
forming the codes of planning and architecture (Sennett, 2018). From this perspective, it would not be wrong to support Klaus (2020)'s statement that "disease shapes cities" by saying that urban forms similarly play an important role in people's health (Binkovitz, 2019), pandemic shape roads, buildings, squares, i.e. common spaces, by putting public health at the center. Although Kimmelman (2020) defines many pandemics as "anti-urban" because they hurt people's sense of togetherness and socialization, these contrasts show how cities should be planned.

The findings of the studies conducted during the pandemic period revealed that the epidemic required a reconsideration of the city in terms of size, urban density, self-sufficiency, use of public transport, providing open space, housing design and better planning for the future (Bolleter, et al., 2021).

From the 19th century to the present, there are studies that describe the street setup and accessibility, analyze social relations with surveys by including the concepts of transportation and neighborhood units such as accessibility, standard distance, common, physical activity, and moreover, reconcile both social and spatial sustainability in neighborhood planning. The garden city, which is accepted as the beginning of the literature, shaped the concept of neighborhood unit design within the framework of a primary school (Howard, 1898). Perry (1929) determined the strengths and weaknesses of the concept and guided the walking distance to be an important factor.

Rosin (1998), used the concept of "Street as Commons" for streets. With the oncoming of the 2000s, research has been developed to create safer and more livable neighborhoods, with the view that residential streets are generally used as areas where local residents can gather. Sustainable planning has been focused on, depending on the environmental pollution experienced with the development of technology. Frischmann (2005) developed the term "infrastructure commons" and evaluated the physical systems developed by people for the public within this concept.

Neighborhoods can become common, with their users accessing all the values and services that the neighborhood offers. While the concept of "accessibility" is the subject of research for equal service to all, Lund (2002), Rogers and Sukolratanametee (2009) define attractive, accessible, connected, mixed, walkable and green streets as pedestrian friendly in their studies, and such connections are more social. He stated that it leads to a chance for interaction and contributes to a sense of community. In the last period, articles and literature on walkability and public health have increased in the lives of people who have 
moved away from public transportation with the Pandemic crisis and stayed with their neighborhoods.

Covid-19 closures did not reduce people's desire for open space, but on the contrary increased it and enabled them to realize multifunctional, flexible and creative applications in common areas (Rosel, 2020). The streets have fed the social life, leisure and recreation, and they have emerged as a part of the social infrastructure (Glover, 2020). Dead-end streets, car parks, car-free streets and sidewalks have turned into event venues, areas of contact and solidarity with neighbors within social distance (Mehta, 2020).

The dissemination of practices such as "shared streets and quiet streets" has supported the increase in walking and cycling in streets and avenues (Sharifi and Khavarian-Garmsir, 2020). Studies that did not make their voices heard before the pandemic for a sustainable life, such as the "Shared Streets Application" defined as "Pedestrian Priority Streets" or "Living Streets" (Home Zone, Woonerf) and "Ciclovias Recreativas - Main Streets Event for Traffic" in Latin America, suddenly became the most popular policies.

Covid-19 Pandemic has supported the neighborhood setup, the accessibility of social facilities and the necessity of walkable streets in relation to the benefits they provide in terms of public health. Furthermore, it revealed the role and importance of the design principles of the neighborhood in the formation of livable and resilient cities with the environment-friendly, connected, and pedestrian and bicycle priority street settings.

According to the results of this review, studies on "street" and/or "neighborhood" have increased in number, and Covid-19 Pandemic highlights open spaces and neighborhood scale once again in the urban planning history.

Designing living environments at neighborhood scale is important for public health and well-being. Planning, urban design, landscape design, architecture, industrial design and the other disciplines that we cannot name here have the responsibility of producing the environment we live in with an interdisciplinary approach. These disciplines should aim to create more livable, more walkable and more socially conducive living environments during the Pandemic and recovery process after it.

\section{Kaynakça/References}

Abass, Z., Andrewsc F. ve Tuckera R.(2020). Socializing in the suburbs: Relationships between neighbourhood design and social interaction in low-density housing contexts. Journal of Urban Design, 25:1, 108-133. doi:10.1080/13574809.2019.1592663. 
Aftabuzzaman, M., Currie, G. ve Sarvi, M. (2010). Evaluating the congestion relief impacts of public transport in monetary terms. Journal of Public Transportation, 13(1), 1-24. doi:10.5038/2375-0901.13.1.1.

Ajuntament de Barcelona (2020). Vallcarca i Penitents. 13 Aralık 2021 tarihinde

https://ajuntament.barcelona.cat/gracia/es/el-distrito-y-sus-barrios/vallcarca-i-elspenitents adresinden erişildi.

Akcan, E. (2020, 28 Nisan). How to build a better world-a part of a cross-disciplinary series examining the real and possible effects of the COVID-19. The Magazine of the Radcliffe Institute for Advanced Study at Harvard University. 13 Aralı 2021 tarihinde https://www.radcliffe.harvard.edu/news-and-ideas/how-to-build-abetter-world adresinden erişildi.

Alter, L. (2020, 20 Nisan). Urban design after the coronavirus. Treehugger. 13 Aralık 2021 tarihinde https://www.treehugger.com/urban-design/urban-design-aftercoronavirus.html adresinden erişildi.

American Planning Association (Amerika Planlama Birliği) (2017). Characteristics and guidelines of great neighborhoods. 13 Aralı 2021 tarihinde https://www.planning.org/greatplaces/ adresinden erişildi.

Appleyard, D. ve Lintell, M. (1971). Environmental quality of city streets: The residensts viewpoint. Highway Research Record; 170.

Ball, S.,(2020,24 Mart). 100,000 cameras: Moscow uses facial recognition to enforce quarantine. France 24. 13 Aralı 2021 tarihinde https://www.france24.com/en/20200324-100-000-cameras-moscow-uses-facialrecognition-to-enforce-quarantine adresinden erişilmiştir.

Barlas, A. (2012). Komşuluk Birimi. Melih Ersoy (Der.) Kentsel Planlama Ansiklopedik Sözlük içinde (ss. 281-283). İstanbul: Ninova Yayıncilık.

Basiago, A. D. (1996). The search for the sustainable city in 20th century urban planning. The Environmentalist, 16, 135-155.

Berg, R.(2020, 14 Nisan). COVID-19 şehir planlamasını nasıl etkileyecek?. WRI Ross Center for Sustainable Cities. 13 Aralı 2021 tarihinde https:/thecityfixturkiye.com/kovid-19-sehir-planlamasini-nasil-etkileyecek/ adresinden erişildi.

Beatley, T. ve Brower, D. J. (1993). Sustaniability comes to main street planning. American Planning Association. 59(5):16-19.

Binkovitz,L. (2019,7 Ocak). The connection between urban planning and your health. Health, Urban Planning. 13 Aralik 2021 tarihinde https://kinder.rice.edu/urbanedge/2019/01/07/connection-between-planningand-your-health adresinden erişildi.

Bliss, L. (2020, 3Nisan). Mapping how cities are reclaiming street space. CityLab. 13 Aralık 2021 tarihinde https://www.citylab.com/transportation/2020/04/coronavirus-city-street-publictransit-bike-lanes-covid-19/609190/ adresinden erişildi. 
Bolleter, J., Edwards, N., Cameron R., Duckworth, A., Freestone, R., Foster, S. ve Hooper, P. (2021). Implications of the COVID-19 pandemic: Canvassing opinion from planning professionals. Planning Practice and Research. doi:10.1080/02697459.2021.1905991.

Brelsford, C., Martin, T., Hand, J. ve Bettencourt, L.M.A.B. (2018). Science Advances;4: eaar4644

Calgary Regional Partnership(Calgary Bölgesel Birliği) (2011). Greenfield tool box for implementation of the calgary metropolitan plan's compact settlement land use and development policies.

Cerin, E., Zhang, C.J., Barnett, A., Sit, C.H., Cheung, M.M., Johnston, J.M. (2016). Associations of objectively assessed neighborhood characteristics with older adults' total physical activity and sedentary time in an ultra-dense urban environment. Health Place, 42, 1-10.

Cole, W. (2020, 13 Nisan). South Korea vows to strap gps tracker wristbands on lockdown flouters. Mail Online. 13 Aralı 2021 tarihinde https://www.dailymail.co.uk/news/article-8212355/South-Korea-vows-strapGPS-tracker-wristbands-lockdown-flouters-stem-coronavirus-spread.html adresinden erişildi.

Corraliza, J. (2000). Landscape and social identity: The construction of territorial identity. Proceeding Soft The 16th Conference of the International Association for PeopleEnvironment Studies, Paris.

Daneshpour, Z.A. (2020). Out of the coronavirus crisis, a new kind of urban planning must be born. ResearchGate. doi: 10.13140/RG.2.2.17931.44322

Duany, A. ve Plater-Zyberk, E. (1994). The neighborhood, the district and the corridor. The New Urbanism: Toward an Architecture of Community, McGraw-Hill, New York, xvii-xx.

Dursun, D. (2020). “COVID-19 sonrası şehirciliği yeniden ele almak: Bağışıklık gü̧̈lendiren kentler". 13 Aralık 2021 tarihinde https://ozgurdenizli.com/covid-19-sonrasisehirciligi-yeniden-ele-almak-bagisiklik-guclendiren-kentler-dogan-dursun/ adresinden erişildi.

Elegant, X.N. ve Chandler, C., (2020,20 Nisan). When red is unlucky: What we can learn from China's color-coded apps for tracking the coronavirus outbreak. Fortune. 13 Aralik 2021 tarihinde https://fortune.com/2020/04/20/china-coronavirustracking-apps-color-codes-covid-19-alibaba-tencent-baidu/ adresinden erişildi.

Erdoğanaras, F., Cihangir Çamur, K., Görer Tamer, N., Mercan, K. (2020). COVID-19, mahalle, müşterekler, kentsel yaşam ve halk sağlı̆̆1 . Türk Coğrafya Dergisi , COVID-19 Özel Sayısı ,76,115-128. doi: 10.17211/tcd.816835.

Ercoşkun, Ö.Y.(2018). Sürdürülebilir kentsel planlama ve tasarım: Dünya örnekleri, Ankara: Gazi Kitabevi.

Ersoy, M., (2015). Kentsel Planlamada Standartlar. İstanbul: Ninova Yayıncilı.

Epstein, R.A.(2002).The allocation of the commons: Parking on public roads. Journal of Legal Studies 31(2): 515-544. 
Fainstein, S. S. (2000). New directions in planning theory. Urban Affairs Review,35(4), 451478.

Frischmann, B. M. (2005). An economic theory of infrastructure and commons management. Minnesota Law Review 89(4):917-1030. http://law.bepress.com/cgi/viewcontent.cgi?article=2998\&context=expresso

Farr, D. (2008). Sustainable urbanism: Urban design with nature. Hoboken, New Jersey: John Wiley \& Sons.

Global Designing Cities Initiative (2020). 13 Aralık 2021 tarihinde https://globaldesigningcities.org/ adresinden erişildi.

Glover, T.D.(2020). Neighboring in the time of coronavirus? paying civil attention while walking the neighborhood. Leisure Sciences, 43,1-2, 280-286. doi:10.1080/01490400.2020.1774014.

Gray, N. (2020, 21 Ekim). In a land of cul-de-sacs, the street grid stages a comeback. Bloomberg City Lab. 13 Aralik 2021 tarihinde https://www.bloomberg.com/news/articles/2020-10-21/scrap-that-cul-de-sacsuburbia-the-grid-is-back?srnd=citylab adresinden erişilmiştir.

Gül, Y., Sultan, Z. ve Jokhio,G.A. (2020). Contribution to the environmental sustainability by improving the walking behaviour through neighbourhoods design with special reference to developing countries. E3S Web of Conferences 158, 02002.

Hall, E.T.(1996). The hidden dimension. NewYork: Doubleday.

Honey-Roses, J., Anguelovski, I., Bohigas, J., Chireh, V., Daher, C., Konijnendijk, C., ve Nieuwenhuijsen, M. (2020, 21 Nisan). The impact of COVID-19 on public space: a review of the emerging questions. 13 Aralık 2021 tarihinde https://osf.io/rf7xa/ adresinden erişildi.

Howard, E.(1898). Garden cities of to-morrow, London: S. Sonnenschein \& Co, 1902.

Hur, M., Nasar, J.L. ve Chun, B. (2010). Neighborhood satisfaction, physical and perceived naturalness and openness. Journal of Environmental Psychology 30 (1): $52-59$.

Ioannou, B. (2019). Ageing in suburban neighbourhoods: Planning, densities and place assessment.Urban Planning, Volume 4, Issue 2, 18-30.

Keleş, R. (2021). Kent bilim terimleri sözlüğ̈̈̈. (3.bs.) İmge Kitabevi, Ankara.

Kennett, P. ve Forrest, R. (2006). The neighbourhood in a European context. Urban Studies, 43(4), 713-718. doi:10.1080/00420980600597368.

Kerr, J., Carlson, J.A, Sallis, J.F., Rosenberg, D., Leak, C.R., Saelens, B.E.(2011) Assessing health-related resources in senior living residences. J. Aging Stud. 25(3), 206-14.

Kılınçaslan, T. (Der.). (2012). Kentsel ulaşım, Ninova Yayıncılık, İstanbul.

Kimmelman, M. (2020, 22 Mart). Can city life survive coronavirus?. The Newyork Times. 13 Aralı 2021 tarihinde https://www.nytimes.com/2020/03/17/world/europe/coronavirus-city-life.html adresinden erişildi. 
Klaus, I. (2020,6 Mart). CityLab. 13 Aralık 2021 tarihinde http://www.kadikoyakademi.org/pandemiler-ayni-zamanda-bir-kentselplanlama-sorunudur/ adresinden erişildi.

Kumlu, K.B.Y., Tüdeş, Ş., Keleş, R. (2018). Komşuluk Birimi Ölçeğinde Yapılı Çevreyi Biçimlendiren Planlama Kararlarına İlişkin Sonuçların Ölçülmesine Yönelik Çok Değişkenli Bir Yöntem Önerisi. Planlama 2018;28(3):328-347

Lund, H. (2002). Pedestrian environments and sense of community. Journal of Planning Education and Research, 21(3): 301-312.

Matthews, J. W. ve Turnbull, G.K. (2007). Neighborhood street layout and property value: The interaction of accessibility and land use mix. The Journal of Real Estate Finance and Economics 35 (2): 111-41.

McCormack GR, Shiell A, Giles-Corti B, Begg S, Veerman JL, Geelhoed E(2012) The Association Between Sidewalk length and walking for different purposes in established neighborhoods. Int $J$ Behav Nutr Phys Act.; 9(1):92. https://doi.org/10.1186/1479-5868-9-92 PMID: 22853008

Mehta, V. (2020). The new proxemics: COVID-19, social distancing, and sociable space. Journal of Urban Design. 25(6), 669-674. doi:10.1080/13574809.2020.1785283.

National Association of City Transportation (NACTO) Officials \& Global Designing Cities (GDCI) Initiative. (2020). Streets for Pandemic Response E Recovery, 2-49.

Nieuwenhuijsen, M.J. (2020). Urban and transport planning pathways to carbon neutral, liveable and healthy cities; a review of the current evidence. Environment International. doi:10.1016/j.envint.2020.105661.

O'Sullivan, F. (2021,2 Mart). Where the '15-minute city' falls short. Bloomberg CityLab. 13 Aralı 2021 tarihinde https://www.bloomberg.com/news/articles/2021-0302/the-downsides-of-a-15-minute-city adresinden erişildi.

O'Toole, R. (2020,20 Mart). Did bad city planning make the coronavirus crisis worse? will we ever learn?.The National Interest. 13 Aralı 2021 tarihinde https://nationalinterest.org/blog/buzz/did-bad-city-planning-makecoronavirus-crisis-worse-135782 adresinden erişildi.

Oflaz, M. (2020, 22 Nisan). COVID-19 sonrası şehir planlama. 13 Aralık 2021 tarihinde http://impoimar.com/blog/14 adresinden erişildi.

Ökten, S. (2014). Fincanımda cola var! , 1. Baskı, İstanbul: Tuti Kitap.

Özüduru, B. H. (2020). COVID-19 ve şehirler. Ankara: İdealKent Yayınları.

Park, Y. ve Rogers, G. O. (2015). Neighborhood planning theory, guidelines, and research: can area, population, and boundary guide conceptual framing? Journal of Planning Literature 2015, Vol. 30(1) 18-36.doi: 10.1177/0885412214549422

Perry, C.A. (1929). The neighborhood unit: A scheme of arrangement for the family-life. Community Regional Plan of New York and Its Environs. New York: Arno Press.

Poovanna, S., (2020, 8 Nisan). Drones used to monitor body temperature, people movement in south bengaluru. Livemint. 13 Arallk 2021 tarihinde https://www.livemint.com/news/india/drones-used-to-monitor-body- 
temperature-people-movement-in-south-bengaluru-11586361317500.html adresinden erişildi.

Porta, S., ve Renne, J. L. (2005). Linking urban design to sustainability: formal indicators of social urban sustainability field research in Perth, Western Australia. Urban Design International, 10(1), 51-64. http://doi.org/10.1057/palgrave.udi.9000136.

Primerano, F. (2003). Towards a policy sensitive accessibility measure. 26th Australian Transport Research Forum, Wellington New Zealand.

Purdom, C.B. (1913). The garden city; a study in the development of a modern town. Printed In The Garden City At The Temple Pres.London.

Rabl, A., Nazelle A. (2012). Benefits of shift from car to active transport. Transport Policy. 19: 121-131.doi: 10.1016/j.tranpol.2011.09.008.

Register, R. (2006). EcoCities: Rebuilding cities in balance with nature. New Society Publishers. Kanada.

Reuters (2020, Nisan 6). Quarantine culture from rooftops, balconies and windows. $\begin{array}{lllll}\text { Reuters. } & 12 & \text { Aralik } & 2021 & \text { tarihinde }\end{array}$ https://www.reuters.com/news/picture/quarantine-culture-from-rooftops-balconiidUSRTS373GI)adresinden erişildi.

Roberts, D.(2020). How to make a city livable during lockdown. Vox. 13 Aralık 2021 tarihinde https://www.vox.com/cities-and-urbanism adresinden erişildi.

Rogers, G. O. ve Sukolratanametee, S. (2009). Neighborhood design and sense of community: comparing suburban neighborhoods in Houston Texas. Landscape and Urban Planning, 92: 325-334.

Rohe, W. (2009). From local to global: One hundred years of neighborhood planning. Journal of the American Planning Association, 75:2, 209-230

Rojas-Rueda, D., de Nazelle, A., Teixidó, O. ve Nieuwenhuijsen, M.J., (2012). Replacing car trips by increasing bike and public transport in the greater Barcelona metropolitan area: A health impact assessment study. Environment International, 49, 100-109. doi: 10.1016/j.envint.2012.08.009

Rosin, T.(1998).The street as public commons: A cross-cultural comparative framework for studying waste and traffic in India. Crossing Boundaries, the seventh annual conference of the International Association for the Study of Common Property, June 1014, Vancouver, British Columbia, Canada.

Sakaja, L., Basic, K., Vuk, R., Stiperski, Z. ve Horvat, A. (2019). Accessiblity in Zagreb for power wheelchair users. Hroatski Geografski Glasnik, 81(2).

Saelens, B. E., Sallis, J. F., Frank, L. D. (2003). Environmental correlates of walking and cycling: Findings from the transportation. Urban Design, And Planning Literatures. Ann Behav Med. 2003; 25(2):80-91.

Sennett, R. (2018). Building and dwelling: Ethics for the city. New York: Farrar, Straus and Giroux.

Sharifi, A. (2016). From garden city to eco-urbanism: The quest for sustainable neighborhood development. Sustainable Cities and Society 20, 1-16. 
Sharifi, A. ve Khavarian-Garmsir, A. R. (2020). The COVID-19 pandemic: Impacts on cities and major lessons for urban planning, design, and management. Science of the Total Environment, 749. doi: 10.1016/j.scitotenv.2020.142391.

Silver, C. (1985). Neighborhood planning in historical perspective. Journal of the American Planning Association 51 (2):161-74.

Stein, C. (1942). City patterns, past and future. In The New Pencil Points Series. Stamford, CT: The Pencil Points Press, Inc.

Stavrides, S.(2019), Müşterek Mekan, Müşterekler Olarak Şehir(Çev.C.Saraçoğlu)2.Baskı, İstanbul:Sel Yayıncılık (Ojinal Yayın Tarih,2018)

Tamborrino, R. (2020). Here's how locking down Italy's urban spaces has changed daily life. World Economic Forum. 13 Aralk 2021 tarihinde https://www.weforum.org/agenda/authors/rosa-tamborrino/ adresinden erişildi.

Tekel, A., Tamer-Görer, N.(2016).Yürünebilirlik Kavramı Ve Yürünebilirliği Etkileyen Temel Faktörler, 80 Sonrası Mekan ve Planlama, içinde, ss:207-215, Gazi Üniversitesi Mimarlık Fakültesi, Şehir ve Bölge Planlama Bölümü, Ankara. ISBN: 978-975-507-283-8.

The New York Times (2021, 12 Ekim). 13 Aralı 2021 tarihinde https://www.nytimes.com/news. adresinden erişildi.

Thompson, C. W. (2002). Urban open space in the 21st century. Landscape and Urban Planning, 60(2), 59-72. doi:10.1016/S0169-2046(02)00059-2.

Timmermans, E.J, Schaap, L.A, Visser, M., van der Ploeg, H.P., Wagtendonk, A.J. ve van der Pas, S. (2016). The association of the neighbourhood built environment with objectively measured physical activity in older adults with and without lower limb osteoarthritis. BMC Public Health. 15, 710.

Toprak, İ., Ünlü, A. ve Nes, A. V. (2019). Street networks as places of social interaction in culturally diverse neighbourhoods of Istanbul. Conference: Proceedings of the 12 th Space Syntax Symposium.

USGBC.(2014). US Green Building Council. http://www.usgbc.org/leed

Ülkeryıldız, E. , Vural, D. C., Yıldız, D. (2020). Transformation of public and private spaces: Instrumentality of restrictions on the use of public space during COVID19 pandemic. 3rd International Conference of Contemporary Affairs in Architecture and Urbanism(ICCAUA-2020).

Yang, R., Yan, H., Xiong, W. ve Liu, T.(2013).The Study of pedestrian accessibility to rail transit stations based on klp mode. Procedia - Social and Behavioral Sciences, 96; 714722

Van Holle, V., Van Cauwenberg, J., Gheysen, F., Van Dyck, D., Deforche, B, Van de Weghe, N. ve De Bourdeaudhuij, I. (2016). The association between Belgian older adults' physical functioning and physical activity: what is the moderating role of the physical environment? Plos One, 11(2):e0148398.

Wade, L. (2020). An unequal blow. Science368(6492),700-703. 
Wheeler, S. (2004). Planning for sustainability: Creating livable, equitable and ecological communities. Routledge: London.

WHO Coronavirus (COVID-19) Dashboard. (2021, 12 Aralık). 12 Aralık 2021 tarihinde https://covid19.who.int/ adresinden erişildi

\section{Ekler}

Ek1. 19.yüzyıldan günümüze kadar Sokak Kurgusunu içinde barındıran çalışmalar

\begin{tabular}{|c|c|c|c|}
\hline \multicolumn{4}{|c|}{ Çalışmaya Ait } \\
\hline $\begin{array}{l}\text { Yazar/ } \\
\text { Araştırmacı }\end{array}$ & Yil & Başlık & $\begin{array}{l}\text { +Anahtar Kelime } \\
\text {-Konu }\end{array}$ \\
\hline \multirow{3}{*}{ Howard, E. } & \multirow{3}{*}{1898} & \multirow{3}{*}{ The Garden City } & +Neighborhood Design \\
\hline & & & -Primary Schools \\
\hline & & & -Rail Transportation \\
\hline Purdom, C.B. & 1913 & The Garden City; A Study In & The Development Of The Modern Town \\
\hline \multirow{3}{*}{ Perry, C. } & \multirow{3}{*}{1929} & \multirow{3}{*}{$\begin{array}{l}\text { The Neighborhood Unit: A } \\
\text { Scheme of Arrangement for } \\
\text { the Family-life Community }\end{array}$} & -Neighborhood Design \\
\hline & & & -Elementary School \\
\hline & & & -Standart Measure \\
\hline \multirow{2}{*}{ Stein, C. } & \multirow{2}{*}{1942} & \multirow{2}{*}{$\begin{array}{l}\text { City Patterns, Past and Fu- } \\
\text { ture }\end{array}$} & -Elementary School \\
\hline & & & -Commercial Centers \\
\hline
\end{tabular}

Silver, C. 1985 Neighborhood Planning in Historical Perspective

\begin{tabular}{|c|c|c|c|}
\hline $\begin{array}{l}\text { Beatley, T. ve } \\
\text { Brower, D. J. }\end{array}$ & 1993 & \multicolumn{2}{|c|}{ Sustainability Comes To Main Street Planning } \\
\hline $\begin{array}{l}\text { Duany, A. ve } \\
\text { Plater-Zyberk, E. }\end{array}$ & 1994 & $\begin{array}{l}\text { The Neighborhood, The } \\
\text { District and The Corridor }\end{array}$ & $\begin{array}{l}\text { +A Quarter-MileRadius } \\
\text { +Five Minute Walking Standard } \\
\text { +Proposed Bus Stops }\end{array}$ \\
\hline Basiago, A.D. & 1996 & \multicolumn{2}{|c|}{ The Search For The Sustainable City In 20th Century Urban Planning } \\
\hline Rosin, $\mathrm{T}$. & 1998 & $\begin{array}{l}\text { The Street as Public Com- } \\
\text { mons: A Cross-Cultural } \\
\text { Comparative Framework } \\
\text { for Studying Waste and } \\
\text { Traffic in India }\end{array}$ & -Street As Commons \\
\hline Fainstein, S. S. & 2000 & \multicolumn{2}{|c|}{ New Directions In Planning Theory } \\
\hline Wheeler, S. & 2004 & $\begin{array}{l}\text { Planning For Sustainability: } \mathrm{C} \\
\text { Communities }\end{array}$ & Creating Livable, Equitable,And Ecological \\
\hline Frischmann, B.M. & 2005 & $\begin{array}{l}\text { An Economic Theory of Inf- } \\
\text { rastructure and Commons } \\
\text { Management }\end{array}$ & -Infrastructure Commons \\
\hline $\begin{array}{l}\text { Porta, S. ve } \\
\text { Renne, J.L. }\end{array}$ & 2005 & $\begin{array}{l}\text { Linking Urban Design To } \\
\text { Sustainability: Formal Indi- }\end{array}$ & $\begin{array}{l}\text { +Sustainable } \\
+ \text { Street }\end{array}$ \\
\hline
\end{tabular}




\begin{tabular}{llll} 
& & $\begin{array}{l}\text { catorsof Social Urban Susta- } \\
\text { inability Field Research In } \\
\text { Perth,Western Australia }\end{array}$ & $\begin{array}{l}\text { + indicators } \\
\text { +Social }\end{array}$ \\
\hline Register, R. & $2006 \begin{array}{l}\text { EcoCities: Rebuilding Cities } \\
\text { in Balance with Nature }\end{array}$ & $\begin{array}{l}\text { +Ecological Carrying } \\
+ \text { +Sustainability }\end{array}$ \\
\hline $\begin{array}{l}\text { US Green Building } \\
\text { Council }\end{array}$ & 2006 & $\begin{array}{l}\text { LEED for Neighborhood } \\
\text { Developments }\end{array}$ & $\begin{array}{l}\text { +LEED for Neighborhood Developments } \\
\text { +Transit facilities Civic and Public Space } \\
\text { Farr, D. }\end{array}$ \\
\hline \multirow{2}{*}{2007} & $\begin{array}{l}\text { Sustainable Urbanism: Ur- } \\
\text { ban Design With Nature }\end{array}$ & $\begin{array}{l}\text { +Street patterns } \\
\text { +Sustainable Urbanism }\end{array}$ \\
\hline
\end{tabular}

Matthews, J.W. ve Turnbull, G.K.

Rohe, W.

Duany, A., Speck,
J., ve Lydon, M.

2007

Neighborhood Street Layout and Property Value: The Interaction of Accessibility and Land Use Mix

2009 Hundred Years Of Neigh- +Neighborhood Revitalization

borhood Planning

-Transit-oriented Development

+ Green Design

2010 The Smart Growth Manual + +Healthy Communities

+New Urbanism

-Pedestrian Access to Stores

Neighborhood satisfaction,

2010 physical and perceived na- -Recreational facilities,Open Space

ve turalness and openness

+ Path Analize

+Ulaşım Sistemi

Kılınçaslan, T.,

2012 Kentsel Ulaşım

+Toplu Taşım Planlama

+Politikalar

Yang, R., Yan, H., Xiong, W. ve Liu, T.

2013

The Study of Pedestrian Ac- ${ }^{*}$ Railway Transit cessibility to Rail Transit Stations based on KLP Mode

*Travel Psychology

Neighborhood Planning

Theory, Guidelines, and Re-

Park, Y. ve Rogers, G.O.

2015 search: Can Area, Population, and Boundary Guide Conceptual Framing?

*Pedestrian access-Access Threshold

+Neighborhood Planning

+Hierarchy of Neighborhoods

+Core Facilities

+ Planning Cores

Could strength of exposure

Ivory, V., Blakely,

T., Pearce J. Ve to the residential neighbo-

Witten, $\mathrm{K}$.

2015 urhood modify associations

+Neighborhood-Walkability

+ Physical Activity

+Built Environment-Active Travel between walkability and physical activity?

From Garden City to Eco-

Sharifi, A. urbanism: The Quest For Sustainable Neighborhood Development

+Neighborhood Unit/Planning

+Garden City+Modernism

+Sustainable Neighborhood Development 
+Eco-urbanism+Eco-city

\begin{tabular}{|c|c|c|c|}
\hline $\begin{array}{l}\text { Tekel, A., ve Ta- } \\
\text { mer-Görer, N. }\end{array}$ & 2016 & $\begin{array}{l}\text { Yürünebilirlik kavramı ve } \\
\text { yürünebilirliği etkileyen te- } \\
\text { mel faktörler. }\end{array}$ & $\begin{array}{l}\text {-Yürüme } \\
\text {-Yaşam Kalitesi }\end{array}$ \\
\hline $\begin{array}{l}\text { Van Holle, V., Van } \\
\text { Cauwenberg, J., } \\
\text { Gheysen, F., Van } \\
\text { Dyck, D., De- } \\
\text { forche, B, Van de } \\
\text { Weghe, N. ve De } \\
\text { Bourdeaudhui, I. }\end{array}$ & 2016 & $\begin{array}{l}\text { The Association between } \\
\text { Belgian Older Adults' Phy- } \\
\text { sical Functioning and Phy- } \\
\text { sical Activity: What Is the } \\
\text { Moderating Role of the } \\
\text { Physical Environment? }\end{array}$ & $\begin{array}{l}\text {-Physical Functioning } \\
\text {-High-walkable Neighborhood }\end{array}$ \\
\hline $\begin{array}{l}\text { American Plan- } \\
\text { ning Association }\end{array}$ & 2017 & $\begin{array}{l}\text { Characteristics And Guide- } \\
\text { lines Of Great Neighborho- } \\
\text { ods }\end{array}$ & $\begin{array}{l}\text { Characteristics of Great Neighborhoods } \\
\text { Guidelines of Great Neighborhoods }\end{array}$ \\
\hline $\begin{array}{l}\text { Brelsford, C., Mar- } \\
\text { tin, T., Hand J., } \\
\text { Bettencourt, L. }\end{array}$ & 2018 & $\begin{array}{l}\text { Toward cities without } \\
\text { slums: Topology and the } \\
\text { spatial evolution of neigh- } \\
\text { borhoods }\end{array}$ & $\begin{array}{l}\text { +Neighborhood Topology } \\
\text { +The Access Networks }\end{array}$ \\
\hline Ercoşkun, Y. & 2018 & \multicolumn{2}{|c|}{ Sürdürülebilir Kentsel Planlama ve Tasarım: Dünya Örnekleri } \\
\hline Ioannou, B. & 2018 & $\begin{array}{l}\text { Ageing in Suburban Neigh- } \\
\text { bourhoods: Planning, Den- } \\
\text { sities and Place Assessment }\end{array}$ & $\begin{array}{l}\text { +Liveable Neighbourhood } \\
\text { +Suburban Development } \\
\text { +Urban Densities }\end{array}$ \\
\hline $\begin{array}{l}\text { Keleş, R., Kumlu, } \\
\text { K.B.Y. ve Tüdeş, Ş. }\end{array}$ & 2018 & $\begin{array}{l}\text { Komşuluk Birimi Ölçeğinde } \\
\text { Yapılı Çevreyi Biçimlendi- } \\
\text { ren Planlama Kararlarına } \\
\text { İlişkin Sonuçların Ölçülme- } \\
\text { sine Yönelik Çok Değiş- } \\
\text { kenli Bir Yöntem Önerisi }\end{array}$ & $\begin{array}{l}\text { +Komşuluk Birimi Tasarımı } \\
\text { +Planlama Kararları } \\
\text { +Yapılı Çevre }\end{array}$ \\
\hline $\begin{array}{l}\text { McCormack, G.R., } \\
\text { Koohsari, M.J., } \\
\text { Oka, K., Friedenre- } \\
\text { ich, C.M., Blacks- } \\
\text { taffe, A, Alaniz } \\
\text { F.U., vd. }\end{array}$ & 2019 & $\begin{array}{l}\text { Differences In Transporta- } \\
\text { tion And Leisure Physical } \\
\text { Activity By Neighborhood } \\
\text { Design Controlling For Re- } \\
\text { sidential Choice }\end{array}$ & $\begin{array}{l}\text { +Active Transportation } \\
\text { +Built Environment } \\
\text { +Walkabilitiy }\end{array}$ \\
\hline
\end{tabular}

Sakaja, L., Basic, K., Vuk, R., Stiperski, Z. ve Horvat, $\mathrm{A}$.

Accessibility in Zagreb for power wheelchair users +Accessibility +Barriers To Mobility

\begin{tabular}{|c|c|c|c|}
\hline Stavrides, S. & 2019 & \multicolumn{2}{|c|}{ Common Space-The City Of Commons } \\
\hline $\begin{array}{l}\text { Abass, Z., And- } \\
\text { rews, F. ve Tuc- } \\
\text { kera, R. }\end{array}$ & 2020 & $\begin{array}{l}\text { Socializing in the suburbs: } \\
\text { relationships between ne- } \\
\text { ighbourhood design and } \\
\text { social interaction in low- } \\
\text { density housing contexts }\end{array}$ & $\begin{array}{l}\text {-Street Layout } \\
\text {-Pedestrian Environment } \\
\text { - Public Space Provision }\end{array}$ \\
\hline $\begin{array}{l}\text { Erdoğanaras, F., } \\
\text { Cihangir Çamur, }\end{array}$ & 2020 & & $\begin{array}{l}\text { +Covid 19, Mahalle } \\
\text {-Sosyal Sermaye ve Halk }\end{array}$ \\
\hline
\end{tabular}




\begin{tabular}{|c|c|c|c|}
\hline $\begin{array}{l}\text { K., Tamer, N.G., ve } \\
\text { Mercan, K. }\end{array}$ & & $\begin{array}{l}\text { Covid-19, Mahalle, Müşte- } \\
\text { rekler, Kentsel Yaşam Ve } \\
\text { Halk Sağlığ1 }\end{array}$ & -Fiziksel Aktivite, Sosyal Etkileşim \\
\hline Glover, T. D. & 2020 & $\begin{array}{l}\text { Neighboring in the Time of } \\
\text { Coronavirus? Paying Civil } \\
\text { Attention While Walking } \\
\text { the Neighborhood }\end{array}$ & $\begin{array}{l}\text { +Sidewalks } \\
\text { +Social Affordances; Social Infrastructure } \\
\text { +Covid-19 }\end{array}$ \\
\hline $\begin{array}{l}\text { Gül, Y., Sultan, Z. } \\
\text { ve Jokhio, G.A. }\end{array}$ & 2020 & $\begin{array}{l}\text { Contribution to the Envi- } \\
\text { ronmental sustainability by } \\
\text { improving the walking be- } \\
\text { haviour through neighbo- } \\
\text { urhoods' design with spe- } \\
\text { cial reference to developing } \\
\text { countries }\end{array}$ & $\begin{array}{l}\text {-Environmental Sustainability } \\
\text {-Walking } \\
\text {-Neighborhood Design }\end{array}$ \\
\hline $\begin{array}{l}\text { Honey-Rosés, J. } \\
\text { vd. }\end{array}$ & 2020 & $\begin{array}{l}\text { The Impact of COVID- } 19 \text { on } \\
\text { Public Space: A Review of } \\
\text { the Emerging Questions }\end{array}$ & $\begin{array}{l}\text { +COVID-19, } \\
\text { +Design, Planning } \\
\text { + Public space. }\end{array}$ \\
\hline Mehta, V. & 2020 & $\begin{array}{l}\text { The New Proxemics: } \\
\text { Covid-19, Social Distancing, } \\
\text { And Sociable Space }\end{array}$ & $\begin{array}{l}\text {-Neighborhood Behaviours } \\
\text {-Social Interactions } \\
\text {-Public Spaces }\end{array}$ \\
\hline
\end{tabular}

